\title{
Redefining Corporate Strategic Fit
}

Virginia L. Blackburn

\author{
Charles B. Shrader \\ Iowa State University \\ Ames, lowa
}

A consensus seems to be forming that related corporate acquisitions are superior to unrelated acquisitions. The arguments center around the idea that related acquisitions present greater opportunities for the exploitation of synergies and that any risk reduction benefits of unrelated acquisitions are more easily and cheaply achieved through diversification of individual investor portfolios. In addition, related acquisitions are considered less risky since they do not take the firm into entirely unfamiliar territory. Historically, empirical evidence has supported the prevailing wisdom of "sticking to the knitting" ([11], [10], [1], [7]). More recent evidence, however, indicates that unrelated mergers and acquisitions are positively valued by the market, suggesting the expectation of risk reduction or synergy exploitation ([2], [5]). This more recent empirical evidence and the mere fact that unrelated mergers continue, suggests that the possible risk reduction or synergistic benefits of unrelated mergers has probably been underestimated. Unrelated diversification is generally viewed as precluding synergies other than those related to cash flows. The importance of nonfinancial synergies including those related to multipoint competition, management and market power is minimized. From a diversification standpoint, to argue that individual investors can achieve equivalent results through their own diversification efforts requires assuming that individual investors are equally capable of achieving cash flow and debt capacity synergies resulting from diversification. This is doubtful.

There is also abundant anecdotal evidence that related mergers are not universally successful. Witness the recent failure of United Airlines to successfully exploit the apparent synergies of airlines, car rental, and hotels. Philip Morris also has had diffculty establishing the profitability of Seven-Up and Miller Beer which are related to Philip Morris' traditional product line by virtue of sharing end users and distribution outlets. Recent work also indicates that related diversification efforts are divested no less frequently than unrelated attempts [6].

Overall, it seems clear that the potential synergies of related mergers may sometimes be overestimated or at least more difficult to achieve than originally thought. On the other hand, it appears that unrelated mergers may provide synergistic or risk reduction benefits not previously thought possible. These developments run contrary to current wisdom regarding diversification and consequently deserve some clarification.

Actually two alternative conclusions are suggested by the current evidence. One conclusion might be that the potential of related acquisitions has been historically

Journal of Business Strategies, Volume 7, Number 1 (Spring 1990) 
overestimated while the potential for unrelated acquisitions has been underestimated. An alternative conclusion is that we have simply not captured the most relevant dimensions of relatedness. This latter conclusion would suggest the need to re-evaluate our working definition of relatedness to more accurately specify those aspects of relatedness that lend themselves to the successful exploitation of synergies.

This paper explores the possibility that the concepts of "relatedness" and its corollary "corporate strategic fit" can be redefined to more clearly address the full scope of managerial, structural and competitive decisions embodied in the corporate strategy formulation and implementation process.

Relatedness has traditionally been defined to include horizontal integration, vertical integration and diversification into related product lines. The extent of relatedness is generally construed as the potential for exploiting marketing, manufacturing and distribution synergies. This narrow definition of relatedness fails to capture a number of the dimensions of relatedness that either enhance the strategic position of the firm or contribute to the failure of the firm to successfully integrate the acquisition.

The premise of this paper is that related mergers and acquisitions are superior to unrelated acquisitions, but that the definition of relatedness must be redefined to consider the full range of issues relevant to the successful integration of the acquisition. A more promising definition of relatedness explicitly considers the respective business level strategies of the acquiring and acquired firm. Business level strategy defines the competitive positioning of the firm in its industry. Porter [8] has identified two primary business/competitive strategy alternatives. Firms can establish themselves as the low price provider in the industry. Implicit to the successful implementation of this strategy is the requirement that the firm also maintain a low cost production position. Alternatively, firms can attempt a differentiation strategy whereby the firm establishes the perceived uniqueness of its product to the customer. Successfully differentiated products can, of course, be sold at a premium over non-differentiated products.

As Porter and others have pointed out, the successful implementation of these strategies requires unique resource bases, distinctive competencies, structural and organizational characteristics. These differences further imply differences in managetial style and organizational culture appropriate to low cost/price and differentiation strategies. The following sections of this paper point out how the mixing of strategic orientations, and by definition, firms with different resource, managerial and organizational configurations may result in less than maximum performance of the combined firm.

In general we suggest that if business strategies are consistent, then the problems of integration are minimized and the possibility of synergies exists regardless of the relationship among product lines. On the other hand, mergers between firms who do not pursue similar business/competitive strategies are more likely to fail regardless of the relatedness of product lines. 


\section{Resource Bases}

Porter [8] details very specific resource and skill requirements for the successful implementation of low cost and differentiation strategies. Low cost strategies imply the need for extensive and sustained capital investment, process engineering capabilities, diligent supervision of labor, products designed for ease of manufacture and low-cost distribution systems. From an organizational standpoint, the low-cost strategy requires a generally more structured, tightly controlled organization which relies heavily on quantitative incentive programs. The emphasis by necessity is on cost control and organizational efficiency with innovativeness generally confined to that which has the potential to erhance production efficiency.

An entirely different set of resources, skills and organizational configurations is necessitated by a differentiation strategy [8]. The emphasis here is on marketing capabilities, product innovation, basic research, company reputation and cooperation of distribution channels. Organizations are more loosely structured and rely on subjective performance measures applied in an atmosphere designed to foster individual creativity and cooperation between functional responsibilities.

Clearly, these sets of skills, resources and organizational requirements ate largely mutually exclusive within the same business unit. Unless a firm does all things well and has access to virtually unlimited capital and human resources, they are not likely to successfully pursue both strategic avenues. Partly because of the unique resource and organizational requirements, the exclusivity of low-cost and differentiation strategies at the business level is generally acknowledged. The mutual exclusivity of competitive strategies is, however, not acknowledged at the corporate level. Strategic "fit" at the corporate level is typically not defined in terms of the consistency of the various competitive strategies simultaneously being pursued by the business units within the corporation. Rather it is defined in terms of the relatedness of product lines.

This perspective fails to fully acknowledge the realities of corporate level strategy. As with single business corporation, a multi-business firm operates under a constraint of finite resource availability. Resource constraints are no less salient simply because a business unit becomes a part of a multi-business firm. In fact, resource dilemmas may be exacerbated if related business units pursuing different competitive strategies begin to vie for larger shares of the existing resource base. Consequently, with respect to resource and organizational requirements, it is more appropriate to view business/competitive strategies as mutually exclusive at the corporate level also.

\section{Dominant Logic and Strategic Complexity}

When relatedness is defined as the relatedness of product lines, strategic complexity is generally defined as function of the number of businesses the firm operates in. Little if any mention is made of the uniqueness and number of business level strategies being pursued. It seems appropriate that strategic complexity at the corporate level should be considered both a function of the number of relevant industries and the 
variability of competitive strategies implemented in each. If both aspects of strategic complexity are considered it is clear that strategic complexity at the corporate level can be increased without becoming involved in multiple industries but simply by pursuing multiple competitive strategies among related product lines within a single industry. The complexity of the management process and the need for multiple dominant logic is increased as the strategic variety and complexity of the corporation increases. Prahalad and Bettis ([9], p. 490) define dominant logic as follows:

"A dominant general management logic is defined as the way in which managers conceptualize the business and make critical resource allocation decision-be it in technologies, product development, distribution, advertising, or in human resource management. These tasks are performed by managing the infrastructure of administrative tools like choice of key individuals, processes of planning, budgeting, control, compensation, career management and organization structure."

The tasks associated with dominant general management logic are more likely to vary with respect to business/competitive level strategies rather than with respect to product line variety. For a firm pursuing multiple competitive strategies, at some point the need for multiple dominant logic will exceed the capabilities of management and the performance of the firm is likely to suffer. It is not, however, simply a question of the number of dominant logics required. Dominant logics can also be considered mutually exclusive. The dominant logic required to implement a low-cost strategy is largely inconsistent with that required to implement a differentiation strategy. From this perspective, dominant logic serves as a constraint on the simultaneous pursuit of multiple business/competitive strategies; performance will decline when management is simultaneously required to employ multiple and inconsistent dominant logic.

On the other hand, dominant logic can also be viewed as a resource which if exploited can enhance the overall performance of a diversified firm. Dominant logics are learned tools and experiences that provide management the expertise to make decisions crucial to strategy formulation and implementation. As Prahalad and Bettis point out, dominant logics are derived from the core business which has provided the basis for internal corporate growth. To the extent that the skills and experience inherent to dominant logic can be generalized to related businesses a powerful management synergy can be exploited for the betterment of the combined firm.

Clearly, whether dominant logics are viewed as constraints or resources the implications for corporate diversification strategy are significant. In order to avoid the need for multiple dominant logics and exploit the existing dominant logic, firms are well advised to pursue a single competitive/business level strategy throughout their strategic business units. Businesses that are related in the traditional sense do not necessarily fulfill this criterion. Similarly, combining businesses that are unrelated in the traditional sense does not preclude adherence to the single dominant logic criterion. 


\section{Strategic Capability Transfer}

Lenz [4] has articulated the concept of "strategic capability" to refer to a firm's ability to "successfully undertake action that is intended to affect its long-term growth and development (p. 226)." This concept has since been elaborated in terms of competitive advantage. Competitive advantage is that which makes the firm's products or services preferable to the competition. Strategic capability then is the "firm's ability to use its skills, knowledge, resources or ways of managing to develop or sustain a competitive advantage." ([3], p. 7) As pointed out previously, alternative business/competitive strategies require unique and largely mutually exclusive sets of skills, knowledge bases, resources and management characteristics. Consequently, strategic capabilities might also be considered mutually exclusive and a function of the competitive/business strategy of the firm.

With regard specifically to acquisitions, Jemison makes the distinction between value capture and value creation. Value capture creates no new value and only involves subsuming the value of the acquired firm under the acquiring firm. Value creation results in the value of the combined firm being greater than the sum of the values of the individual firms. For value creation to occur, there must be a transfer of strategic capability between the acquiring and the acquired firm. Further, for strategic capability transfer to be meaningful and viable, both firms should potentially benefit from sharing similar competitive advantages.

This later condition is most likely to occur, of course, when the combining firms are pursuing similar business/competitive strategies. The potential for strategic capability transfer should be greater between firms pursuing consistent business level strategies since the combined firm can exploit those things which individually gave them a competitive advantage. In addition the constraints on effective strategic capability transfer should be minimized when two firms share strategic philosophies and resource bases appropriate to their given business/competitive strategy.

\section{A Redefinition}

We have proposed that the traditional definition of related diversification does not capture the full range of issues important to corporate level strategy formulation and implementation. We do not suggest that these definitions be dropped, but that they be expanded to consider the business/competitive strategy of the firms. These arguments hold regardless of whether the diversification is developed internally or is acquired. It is necessary to explicitly consider both the type of corporate level diversification strategy and type of business level strategy. Corporate level diversification strategy alternatives include horizontal, backward and forward integration, market related diversification, product related diversification and unrelated diversification. Business/competitive strategy alternatives include differentiation or low cost.

The central idea present here is consistency of business strategies is a precondition for successful corporate diversification. The importance of business strategy consistency is a function of the choice of diversification strategy. With respect to horizontal 
integration, forward and backward integration and related diversification, business strategy fit is critical to the successful assimilation of the new operation and the subsequent achievement of desired synergies. Only in the case of unrelated product lines is business strategy fit not entirely necessary to the success of the diversification attempt. Even in this case, however, consistent business strategies among unrelated product lines is advantageous.

It is helpful to consider the necessity of business strategy fit for each of the corporate level strategy alternatives. Horizontal integration involves expansion through acquisition of directly competing firms which by definition offer equivalent product lines. This strategy basically represents an increasing commitment to a concentration strategy. Although product lines are equivalent the two firms may be pursuing different competitive strategies prior to acquisition. If so, the differences in required resource bases and organizational configurations will preclude most expected synergies and make it extremely difficult to assimilate the acquired firm. From the customer's perspective, mixing of competitive strategies may create confusion, consequently threatening the viability of both competitive strategies.

Vertical integration involves moving forward or backward along the production/ distribution chain. The potential benefits of integration include reliable, cost efficient supply sourcing or product outlets, smoothing of scale economies and absorption of profit centers. The pursuit of either backward or forward vertical integration should ideally enhance the firm's ability to pursue either a low cost or differentiation strategy within their core business. For this to occur, it is necessary that the acquired firm pursue a business level strategy consistent with that of the focus firm. Otherwise the strategy of the focus firm may be undermined by attempting to assimilate inconsistent strategies. For example, the cost of supplies will be a function of the strategy pursued by the acquired firm. It will likely not be cost effective for a firm pursuing a low cost strategy to purchase a firm pursuing differentiation in order to establish a low cost, reliable source of supply. Levels of scale economies are also likely to be different for low cost and differentiated producers. Consequently, the desired benefit of smoothed scale economies may be difficult to achieve when mixing business level strategies. Finally, the price/cost structure of low cost producers and differentiators is not similar, thereby reducing the value of the acquired firm as a profit center.

Finally, in the case of unrelated acquisitions, it is probably less important that consistency of business level strategies be maintained. Among unrelated businesses, the potential for some synergies and consequently, the need for integration into the existing organization is lower. On the other hand, consistency of strategic orientations among unrelated product lines may result in synergies associated with resource allocations, managerial talent and dominant logic. Management may be able to apply, in unrelated areas, those skills that provided them their competitive advantage within their focus industry. Inconsistency of business level strategies may not preclude unrelated diversification, however, consistency of strategies may often go unexploited as a major source of potential synergies. 


\section{Conclusion}

This article has outlined the arguments supporting a redefinition of relatedness and corporate strategic fit. In sum it is suggested that definitions of relatedness in terms of product line characteristics do not capture the full range of resource, competitive, management and organizational issues relevant to the successful integration of diversification efforts. A more promising conceptualization considers an additional aspect of relatedness regarding the consistency of competitive strategies across strategic business units. It is argued here that inconsistency of business unit competitive strategies can undermine efforts to achieve synergies through related diversification. With respect to unrelated diversification, inconsistency of competitive business strategies may not preclude integration of new diversification efforts. If, however, the unrelated product lines share common competitive strategies, managerial and organizational synergies which would otherwise be unattainable may be exploited.

\section{References}

1. Christensen, H. K. and C. A. Montgomery. "Corporate Economic Performance: Diversification Versus Market Structure." Strategic Management Journal, Vol. 2 (1981), pp. 327-43.

2. Elgers, P. T. and J. J. Clark. "Merger Types and Shareholder Returns: Additional Evidence." Financial Management, Vol. 9 (1980), pp. 66-72.

3. Jemison, D. B. "Process Constraints on Strategic Capability Transfer During Acquisition Integration." Paper presented at the Academy of Management, New Orleans, LA (August, 1987).

4. Lenz, R. T. "Strategic Capability: A Concept and Framework for Analysis." Academy of Management Review, Vol. 5 (1980), pp. 225-34.

5. Lubatkin, M. "Merger Strategies and Stockholder Value." Strategic Management Journal, Vol. 8 (1987), pp. 39-53.

6. Montgomery, C. A. and V. A. Wilson. "Mergers That Last: A Predictable Pattern?" Strategic Management Journal, Vol. 7 (1986), pp. 91-96.

7. Peters, T. J. and R. H. Waterman, Jr. In Search of Excellence. New York, NY: Harper \& Row (1982).

8. Porter, M. E. Competitive Strategy. New York, NY: Free Press (1980).

9. Prahalad, C. K. and R. A. Bettis. "The Dominant Logic: A New Linkage Between Diversity and Performance." Strategic Management Journal, Vol. 7 (1986), pp. 485-501.

10. Rumelt, R. P. "Diversification Strategy and Profitability." Strategic Management Journal, Vol. 3 (1982), pp. 352-69.

11. Rumelt, R. P. Strategy, Structure and Economic Performance. Boston, MA: Harvard University Press (1974). 